07

\title{
Электролюминесцентные исследования эффективности кремниевых гетероструктурных солнечных элементов
}

\author{
(C) В.Н. Вербицкий ${ }^{1}$, И.Е. Панайотти ${ }^{1}$, С.Е. Никитин ${ }^{1}$, \\ А.В. Бобыль ${ }^{1}$, Г.Г. Шелопин ${ }^{2}$, Д.А. Андроников ${ }^{2}$, \\ А.С. Абрамов ${ }^{2}$, А.В. Саченко ${ }^{1}$, Е.И. Теруков ${ }^{1,2}$
}

${ }^{1}$ Физико-технический институт им. А.Ф. Иоффе РАН, Санкт-Петербург ${ }^{2}$ НТЦ тонкопленочных технологий в энергетике при Физико-техническом институте им. А.Ф. Иофрфе, Санкт-Петербург

E-mail: vnverbitskiy@mail.ru

Поступило в Редакцию 16 сентября 2016 г.

Впервые обнаружено сильное изменение интенсивности электролюминесценции (более чем на порядок) в высококачественных гетеропереходных солнечных элементах на основе монокристаллического кремния при изменении их эффективности от 18 до 20.5\%. Причинами эффекта являются резкое изменение концентрации центров рекомбинации на поверхности пластин монокристаллического кремния в процессе их пирамидального текстурирования, а также увеличение последовательного сопротивления. Обнаруженный эффект может быть использован для количественной высокочувствительной характеризации текстурирования - принципиально важного этапа изготовления высокоэффективных кремниевых солнечных элементов.

DOI: 10.21883/PJTF.2017.17.44940.16479

Исследования, направленные на совершенствование технологических процессов производства кремниевых гетеропереходных солнечных элементов - HIT (heterojunction with intrinsic thin-layer solar cells)- 
элементов, активно ведутся в отечественных и зарубежных научных центрах. Одним из перспективных методов контроля качества полупроводниковых структур является регистрация уровня электролюминесценции фотоэлектрических преобразователей (ФЭП) [1]. Целью настоящей работы является исследование связи между интенсивностью электролюминесценции и эффективностью НІТ-элементов.

Для решения поставленной задачи была изготовлена опытная партия образцов НІТ-элементов, сформированных на монокристаллических кремниевых пластинах $n$-типа с кристаллографической ориентацией $(100)$, размером $156 \times 156 \mathrm{~mm}$ и толщиной $180 \mu \mathrm{m}$. При этом использовались кремниевые пластины, вырезанные из одной и той же части слитка монокристаллического кремния $(c-\mathrm{Si})$, выращенного методом Чохральского $(\mathrm{Cz})$. Все образцы изготавливались в одинаковых технологических условиях, за исключением этапа химической обработки пластин, в течение которого текстурирующий раствор не менялся на протяжении нескольких циклов. Химическая обработка пластин заключалась в последовательном прохождении кассеты с 24 пластинами через ванны с химическими растворами и включала следующие основные стадии: очистку поверхности от загрязнений; текстурирование в щелочном растворе $\mathrm{KOH}$ с добавлением поверхностно-активной добавки (изопропилового спирта) - формирование пирамидальной морфологии; финишную очистку. Стадии химической обработки более подробно рассмотрены в работах [2,3]. Последующие этапы формирования НIT-структуры заключались в нанесении слоев аморфного кремния методом газофазного осаждения (PECVD), напылении прозрачных проводящих электродов (оксид индия-олова) и формировании контактной сетки. Более подробно основные технологические этапы изготовления НІТ ФЭП рассмотрены в работах [4,5]. Полупроводниковая структура изготовленных НІТ-элементов изображена на рис. 1,a. Монокристаллическая подложка $c$-Si имеет следующие параметры: концентрация доноров $N_{d} \approx 10^{15} \mathrm{~cm}^{-3}$, толщина $d \approx 170 \mu \mathrm{m}$ (среднее значение после химической обработки), объемное время жизни носителей заряда $\tau \approx 1.5 \mathrm{~ms}$. Площадь ФЭП равна $239 \mathrm{~cm}^{2}$.

Поскольку процесс текстурирования проходил в одном и том же химическом растворе объемом 101, в нем постепенно (от цикла к циклу) накапливались продукты взаимодействия с кремнием. Взаимодействие кремния и текстурирующего раствора описывается химической 

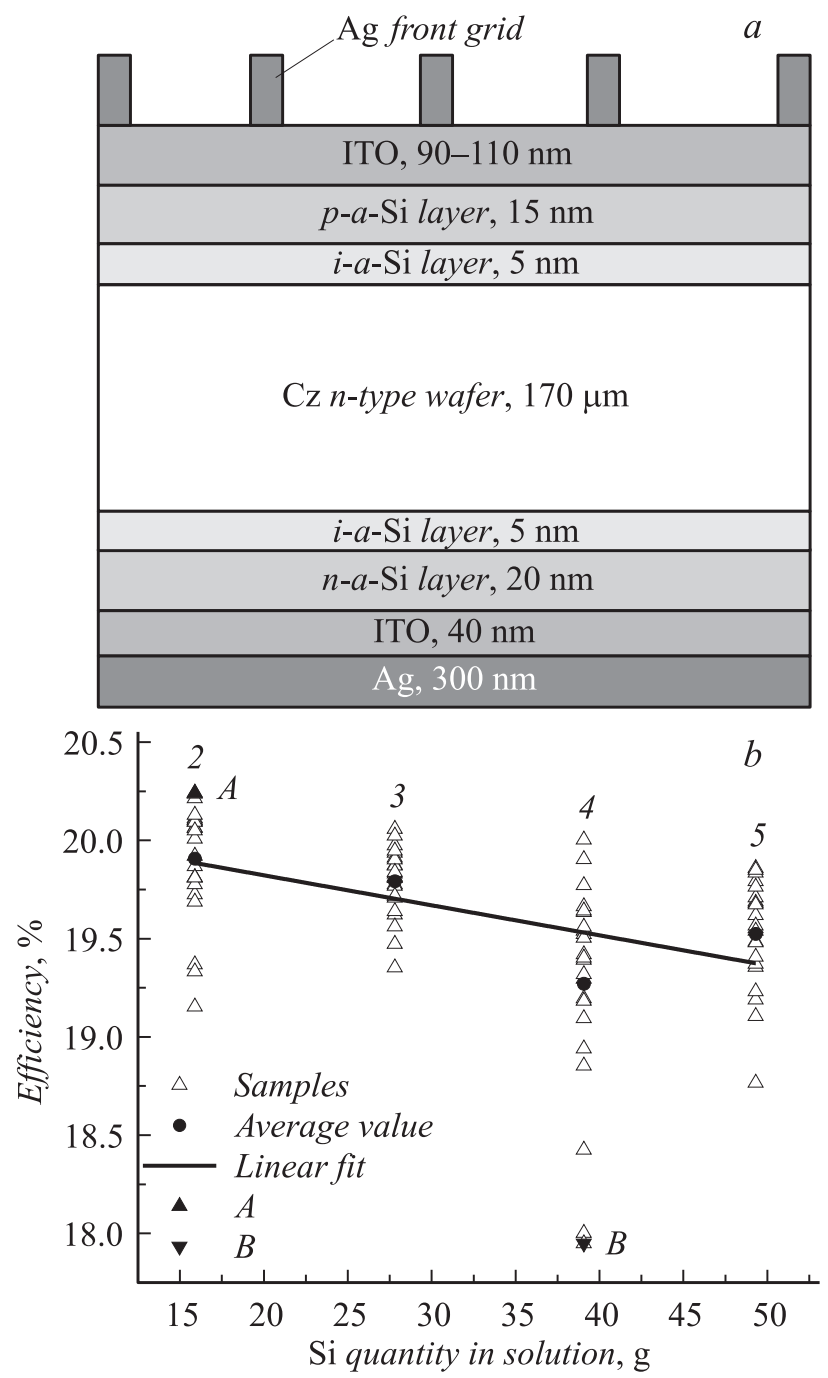

Рис. 1. Схематическое изображение НІТ-элемента $(a)$ и распределения эффективностей изготовленных образцов (цифрами отмечена очередность текстурирования) (b).

Письма в ЖТФ, 2017, том 43, вып. 17 
Параметры образцов

\begin{tabular}{c|c|c|c|c|c}
\hline Образец & EL, a.u. & $\begin{array}{c}\text { Напряжение } \\
\text { холостого } \\
\text { хода, V }\end{array}$ & $\begin{array}{c}\text { Ток } \\
\text { короткого } \\
\text { замыкания, A }\end{array}$ & $\begin{array}{c}\text { Мощность, } \\
\text { W }\end{array}$ & $\begin{array}{c}\text { Эффективность } \\
\text { НІТ-элемента, } \\
\%\end{array}$ \\
\hline$A$ & 126.94 & 0.729 & 8.70 & 4.84 & 20.24 \\
$B$ & 11.28 & 0.690 & 8.60 & 4.27 & 17.85
\end{tabular}

Примечание: EL - электролюминесценция, определенная как средневзвешенный уровень яркости пикселей изображения (photoshop), который получается путем умножения каждого уровня яркости на число пикселей данного уровня, а затем делится на общее число уровней яркости.

реакцией с образованием силиката калия

$$
\mathrm{Si}+2 \mathrm{KOH}+\mathrm{H}_{2} \mathrm{O}=\mathrm{K}_{2} \mathrm{SiO}_{3}+2 \mathrm{H}_{2} \uparrow .
$$

Процесс протекает при температуре $70-80^{\circ} \mathrm{C}$, когда происходит интенсивный гидролиз силиката калия с образованием геля оксида кремния. При больших концентрациях силиката калия оксидная пленка $\left(\mathrm{SiO}_{2}\right)$, образующаяся в результате гидролиза, затрудняет транспорт реагентов к поверхности кремния, что приводит к заметному разбросу скоростей травления на различных микроучастках поверхности кремния. Таким образом, на гранях формирующихся пирамид возрастает вероятность возникновения многочисленных дефектов и ступенек, которые играют роль рекомбинационных центров [6] и негативно сказываются на итоговой эффективности ФЭП. На рис. $1, b$ приведены график распределения эффективностей НІТ-элементов и очередность их текстурирования в зависимости от количества растворенного кремния. Символы $A$ и $B$ на этом рисунке соответствуют образцам на рис. 2 и в таблице.

Измерения характеристик образцов ФЭП проводились на комплексе cetisPV-Celltest3 (HALM, Германия) с приставкой cetisPV-cellEL-Lab (картирование электролюминесценции), оборудованной CCD камерой 1.4 мегапикселя и световыми фильтрами, отсекающими длины волн меньше $880 \mathrm{~nm}$. В результате эксперимента была изучена электролюминесценция более ста солнечных элементов с различными КПД. Все измерения проводились в одинаковых условиях: ток 9 А, напряжение $2 \mathrm{~V}$, экспозиция $40 \mathrm{~ms}$. На рис. 2 и в таблице приведены примеры 

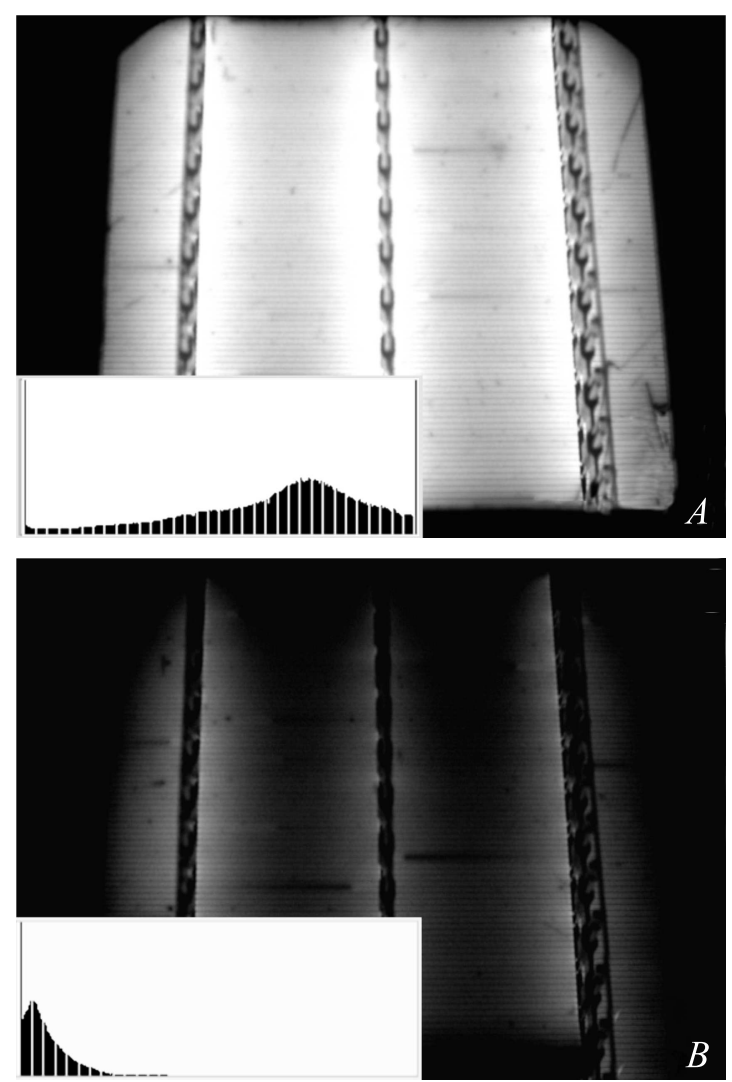

Рис. 2. Снимки образцов с относительно сильной $(A)$ и слабой $(B)$ интенсивностью электролюминесценции.

снимков и параметры образцов с относительно сильной и слабой интенсивностью электролюминесценции (гистограммы яркости и значения интенсивностей получены при обработке карт электролюминесценции в программе photoshop). Экспериментально обнаружено, что снижение эффективности НІТ-элементов на два процента приводит к падению яркости свечения электролюминесценции более чем на порядок рис. $3, a$ (точки).

Письма в ЖТФ, 2017, том 43, вып. 17 

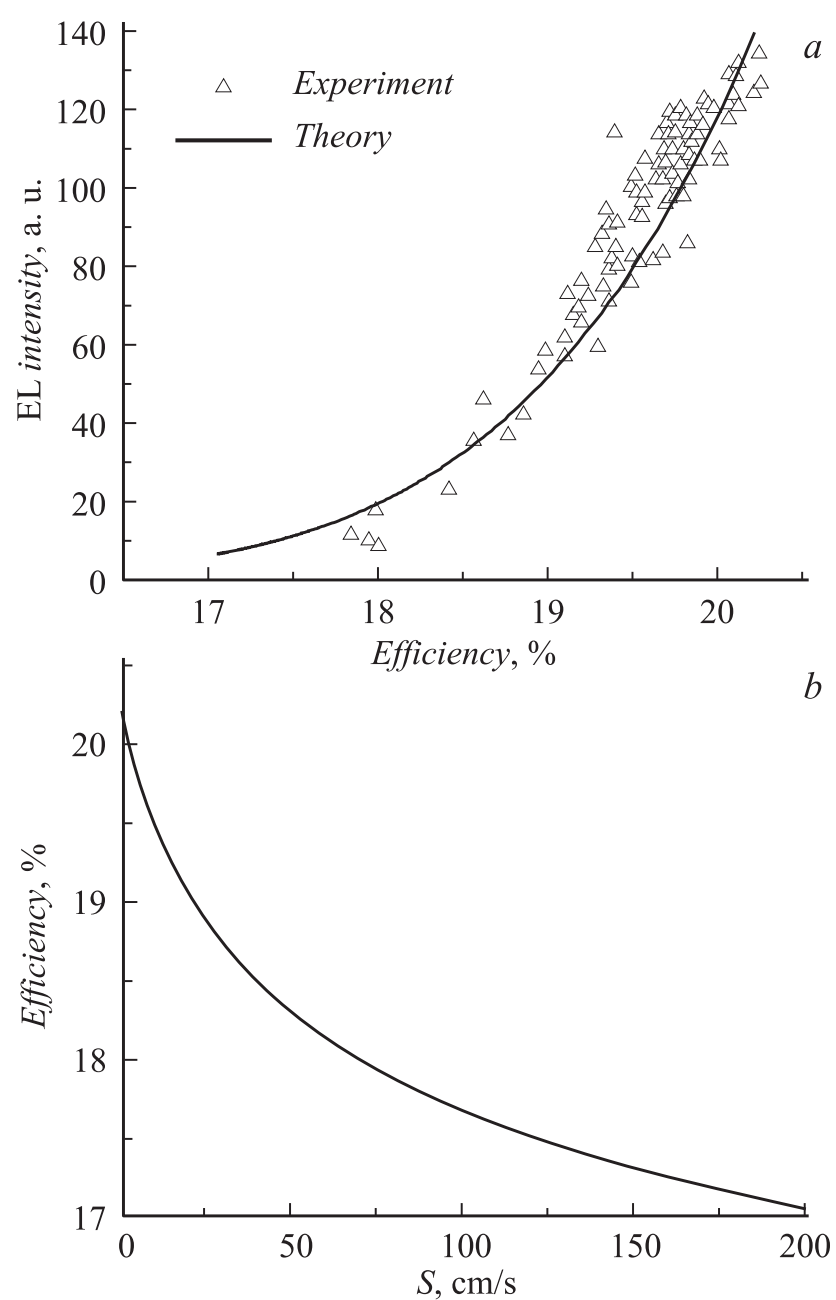

Рис. 3. Экспериментальная и расчетная зависимости интенсивности электролюминесценции от эффективности НІТ-элементов $(a)$ и расчетная зависимость эффективности НIT-элементов от суммарной скорости поверхностной рекомбинации $(b)$. 
Особенности полупроводниковой структуры НІТ-элементов таковы, что концентрации избыточных носителей заряда $\Delta p$ на границах подложки примерно одинаковы, а их диффузионные длины $L_{d i f f}$ всегда настолько велики, что $L_{d i f f} \gg d$. Следовательно, $\Delta p \approx$ const во всех сечениях токового канала, и диффузионные токи в подложке практически отсутствуют. Оценки, проведенные в работе [7], свидетельствуют о том, что, хотя в условиях максимальной мощности уровни инжекции в HIT-элементах невысоки: $\Delta p \leqslant N_{d}$, падения напряжения на подложке не превышают сотых долей вольта. Поэтому дрейфовым механизмом переноса заряда также можно пренебречь. Тогда полная плотность тока $J$ фактически определяется суммарными рекомбинационными потерями $R_{\text {total }}$ в объеме подложки и на ее поверхностях

$$
J \cong J_{\text {rec }} \text { const }
$$

где

$$
J_{\text {rec }}=J_{\text {rec }}^{\text {lum }}+J_{\text {rec }}^{\text {nonlum }}=q\left[\frac{d}{\tau}+S\right] \Delta p \sim R_{\text {total }}
$$

- сумма токов излучательной и безызлучательной рекомбинаций [8], $S$ - суммарная скорость поверхностной рекомбинации. Ток излучательной рекомбинации обусловлен $J_{r e c}^{l u m}$ межзонными переходами в объеме подложки. Интенсивность электролюминесценции $I$ прямо пропорциональна скорости излучательной рекомбинации $R_{l u m}$ и вызванному ею рекомбинационному току

$$
I \sim R_{\text {lum }} \sim J_{\text {rec }}^{\text {lum }} .
$$

Поскольку время жизни носителей заряда велико (более $1 \mathrm{~ms}$ ), концентрация глубоких рекомбинационных центров достаточно мала. Поэтому можно предположить, что безызлучательная рекомбинация в данном случае происходит в основном через уровни на поверхностях подложки и определяется суммарной скоростью поверхностной рекомбинации $S$.

Измерения интенсивности электролюминесценции проводились при одинаковой для всех образцов плотности тока, равной $J=37.65 \mathrm{~A} / \mathrm{cm}^{2}$, которая поддерживалась постоянной. Процессы безызлучательной рекомбинации через поверхностные дефекты конкурируют с излучательной объемной рекомбинацией при постоянной сумме их скоростей. Чем выше скорость безызлучательной поверхностной рекомбинации, тем ниже квантовый выход излучательной объемной рекомбинации, и

Письма в ЖТФ, 2017, том 43, вып. 17 
наоборот. Поскольку подложки всех ФЭП были вырезаны из одного кристалла кремния, величина $\tau$ для них одинакова. Очевидно, что образцы различаются качеством поверхностей, т. е. имеют разные $S$. Так, при указанных выше параметрах $\tau$ и $d$ и при $S=1 \mathrm{~cm} / \mathrm{s}$ имеем $\tau \gg S$. А при $S=100 \mathrm{~cm} / \mathrm{s}$ излучательная рекомбинация будет подавлена и $J_{\text {rec }}^{\text {lum }}$ упадет примерно на порядок. В зависимости от качества поверхности образца меняется соответствующим образом и концентрация избыточных неравновесных носителей заряда $\Delta p$.

Влияние скорости поверхностной рекомбинации на эффективность НІТ-элементов подробно изучено в работе [7]. На основе предложенной в $[8,9]$ теоретической модели была рассчитана зависимость эффективности ФЭП от суммарной скорости поверхностной рекомбинации в условиях АМ1.5 с учетом последовательного сопротивления на единицу площади $R_{S}=0.8 \Omega \cdot \mathrm{cm}^{2}$ (рис. $\left.3, b\right)$.

Учитывая связь между рекомбинационными процессами в объеме подложки и на ее поверхностях (1), (2), можно найти соответствия между $S$ и $I \sim J_{\text {rec }}^{\text {lum }}$ и построить зависимость $I$ от эффективности (рис. 3,a).

Наблюдается качественное и количественное согласие между экспериментальными данными и расчетными результатами при $R_{S}=$ $=0.8 \Omega \cdot \mathrm{cm}^{2}$. Небольшие расхождения могут быть вызваны тем, что теоретическая модель не учитывает разброса параметров, связанного с несовершенством технологических процессов, таких как осаждение слоев аморфного кремния, нанесение прозрачного проводящего электрода (оксида индия-олова) и формирование контактной сетки, а также связаны с имеющимися царапинами, микротрещинами и другими дефектами на пластинах. В частности, качество соединений $p-a-\mathrm{Si} / i-a$ $\mathrm{Si} / n-c-\mathrm{Si}$ и $n-a-\mathrm{Si} / i-a-\mathrm{Si} / n-c-\mathrm{Si}$ может существенно влиять на свойства сформированных гетеропереходов. Снижение их инжектирующей способности ведет к уменьшению концентрации избыточных носителей заряда $\Delta p$, а следовательно, и проводимости в подложке, что является причиной роста последовательного сопротивления. Зависимость снижения эффективности при увеличении $R_{S}$ изучена в [8].

Полученные результаты показывают, что оценка уровня яркости свечения НІТ-элементов при электролюминесценции может служить показателем качества их полупроводниковых структур, в частности поверхности текстурированной подложки и гетеропереходов.

Теруков Е.И. выражает благодарность РФФИ (грант № 16-29-06423) за финансовую поддержку работы.

Письма в ЖТФ, 2017, том 43, вып. 17 


\section{Список литературы}

[1] Фори П.А., Жигунов Д.М., Бобыль А.В. и др. // Аморфные и микрокристаллические полупроводники. Х Междунар. конф. СПб.: ФТИ им. А.Ф. Иоффе PAH, 2016. C. 209-210.

[2] Chu A.K., Wang J.S., Tsai Z.Y., Lee C.K. // Solar Energy Mater. Solar Cells. 2009. V. 93. P. 1276-1280.

[3] Zubel I., Granek F., Rola K., Banaszczyk K. // Appl. Surf. Sci. 2012. V. 258. P. 9067-9072.

[4] Goodrich A., Hacke P. et al. // Solar Energy Mater. Solar Cells. 2013. V. 114. P. $110-135$.

[5] Sachenko A.V., Kryuchenko Yu.V. et al. // J. Appl. Phys. 2016. V. 119. P. 225702.

[6] Игумнов В.Н. // Физические основы микроэлектроники. М.-Берлин: ДиректМедиа, 2015. С. 245-248.

[7] Саченко А.В., Крюченко Ю.В. и др. // ФТП. 2016. Т. 50. В. 2. С. 259-263.

[8] Саченко А.В., Шкребтий А.И. и др. // ФТП. 2015. Т. 49. В. 2. С. 271-277.

[9] Саченко А.В., Крюченко Ю.В. и др. // Письма в ЖТФ. 2015. Т. 49. В 10. C. $42-49$. 